\title{
Application of surface analytical methods for hazardous situation in the Adriatic Sea: monitoring of organic matter dynamics and oil pollution
}

\author{
Galja Pletikapié $^{1, \mathrm{a}}$ and Nadica Ivošević DeNardis ${ }^{1}$ \\ ${ }^{1}$ Division for Marine and Environmental Research, Ruđer Bošković Institute, POB 180, 10000 Zagreb, Croatia \\ ${ }^{a}$ now at: FOM Institute AMOLF, POB 41883, 1009 DB Amsterdam, the Netherlands
}

Correspondence to: Nadica Ivošević DeNardis (ivosevic@irb.hr)

Received: 15 May 2016 - Published in Nat. Hazards Earth Syst. Sci. Discuss.: 6 July 2016

Revised: 30 November 2016 - Accepted: 19 December 2016 - Published: 6 January 2017

\begin{abstract}
Surface analytical methods are applied to examine the environmental status of seawaters. The present overview emphasizes advantages of combining surface analytical methods, applied to a hazardous situation in the Adriatic Sea, such as monitoring of the first aggregation phases of dissolved organic matter in order to potentially predict the massive mucilage formation and testing of oil spill cleanup. Such an approach, based on fast and direct characterization of organic matter and its high-resolution visualization, sets a continuous-scale description of organic matter from microto nanometre scales. Electrochemical method of chronoamperometry at the dropping mercury electrode meets the requirements for monitoring purposes due to the simple and fast analysis of a large number of natural seawater samples enabling simultaneous differentiation of organic constituents. In contrast, atomic force microscopy allows direct visualization of biotic and abiotic particles and provides an insight into structural organization of marine organic matter at micro- and nanometre scales. In the future, merging data at different spatial scales, taking into account experimental input on micrometre scale, observations on metre scale and modelling on kilometre scale, will be important for developing sophisticated technological platforms for knowledge transfer, reports and maps applicable for the marine environmental protection and management of the coastal area, especially for tourism, fishery and cruiser trafficking.
\end{abstract}

\section{Introduction}

Different human activities introducing substances and energy in marine environment can have serious environmental threats with wide ranging impacts and possibly long lasting consequences. The impact of human activities (land-based and marine) on coastal and marine ecosystems, and how to manage them, demonstrates the need for a monitoring study of the environmental status of seawaters, which is the main goal of the Marine Directive. Here, we address the major challenges faced by the Adriatic Sea: risks and threats of oil pollution and mucilage formation, where eutrophication most probably contributes to the frequency of mucilage appearance (Fonda-Umani et al., 1989). The Adriatic Sea is a semi-closed, narrow basin with a northern shallow zone and is thus very sensitive to environmental changes. According to the Croatian Hydrocarbon Agency (www.azu.hr), up to now over 1500 exploration and production wells have been drilled in the Adriatic Sea, with the intention to set up many new ones. On the national level, there is rising concern from both public and environmental agencies about the oil exploitation fields in the Adriatic Sea. Additional risk for oil spill accidents arises from tankers transporting petroleum directed towards transit ports mainly situated in the northernmost part of the Adriatic Sea. However, mucilage or macroscopic gel phase formation manifests itself in episodic appearance of enormous amounts of gelatinous matter in the water column and floating on the sea surface (Fig. 1, Stachowitsch et al., 1990; Svetličić et al., 2005; Giani et al., 2005a). The western part of the Adriatic Sea is eutrophic (due to run-off from the Po River), causing hyper-production of microalgae, mainly 

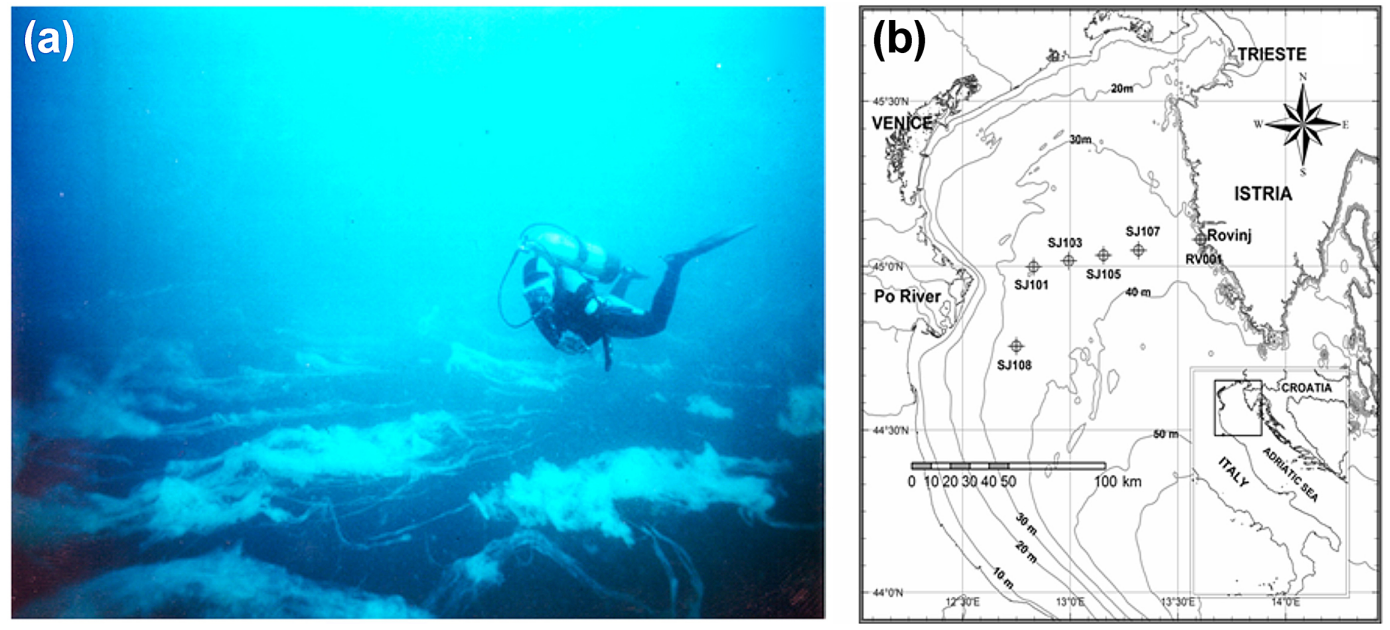

Figure 1. Macroaggregation phenomena in the northern Adriatic: (a) giant gel aggregate at $10 \mathrm{~m}$ depth as captured by a scuba diver in August 1997 (courtesy of Gerald Müler-Niklas) and (b) map of the study area (inset) and sampling stations in the northern Adriatic.

polysaccharides, that accumulate in the euphotic layer. Under certain environmental conditions, a mucilage event occurs. The phenomenon has been observed infrequently over the past 3 centuries, but the frequency has increased during the last 2 decades. This can have harmful consequences for the marine systems and cause substantial damage to the economy of the region (e.g. fisheries, tourism). Even though evidence accumulated from satellite observations to micro-scale studies and a large number of hypotheses on the mechanism of the event have emerged over the last decades (Žutić et al., 2004), what triggers such a large-scale phase transformation of organic matter is still a subject of debate (Giani et al., 2005a).

Organic matter in the water column has a highly reactive nature; it continuously undergoes biotic and abiotic transformations and consequently exhibits high variation in time and space, with a tendency to accumulate at the interfaces. Biogeochemical transformation of organic matter is a rather complex process, in which chemical composition of the seawater plays an important role. The fate of marine organic matter depends not only on the inorganic constituents but also on biota, influencing its physicochemical properties, distribution, stability and bioavailability of metal-organic complexes. Organic matter in the marine environment is classified as dissolved (DOM), consisting of truly dissolved and colloidal fractions, and particulate based on the traditional oceanographic routines. DOM can be produced by phytoplankton, macrophytes and marine plants through primary production (Carlson, 2002), and $10 \%$ of it can self-assemble to form nano-, micro- or even macrogels (Verdugo et al., 2004; Verdugo, 2012). Because of the great complexity and heterogeneous composition of marine organic matter, its characterization remains a challenge. In the following, organic matter characterization is summarized briefly based on the measurement techniques. Characteri- zation of DOM in terms of its composition and molecular structure has advanced substantially in the last decade, mainly due to the development of advanced instrumental analytical methods and the corresponding procedures: for example, Fourier transform ion cyclotron, mass spectrometry, homo- and hetero-correlated multidimensional nuclear magnetic resonance spectroscopy, excitation emission matrix fluorimetry with parallel factor analysis for UV-fluorescence spectroscopy, and advances made in sample preparation (i.e. desalting/extraction techniques; Nebbioso and Piccolo, 2013; Roth et al., 2015; Kujawinski et al., 2016; Mopper et al., 2007). In addition, development of particle counters (electronic, electrochemical), histological staining and sophisticated microscopical methods in the last decades helped establish new particle classes, predominantly non-living, which had remained undetected due to their small size, transparency and susceptibility to degradation (Žutić and Svetličić, 2000). These particle classes have shown large abundance and reactivity, consequently having a crucial role in aquatic environments, particularly in the cycling of nutrients, aggregation of organic matter and the food web (Koike et al., 1990; Wells and Goldberg 1994; Long and Azam, 1996). The abundance of non-living particles greatly exceeds the abundance of living microorganisms, algae and bacteria, and viruses. Major classes of non-living organic particles in euphotic layer are (i) colloidal particles $(5-200 \mathrm{~nm})$ collected by ultracentrifugation and observed under transmission electron microscopy (Wells and Goldberg, 1991, 1993; Kepkay, 1994; Leppard et al., 1997); (ii) submicrometre particles $(0.4-1 \mu \mathrm{m})$ detected by Coulter particle counters (Koike et al., 1990; Longhurst et al., 1992); (iii) surface-active particles (SAP; $1-500 \mu \mathrm{m}$ ) detected electrochemically (Žutić et al., 1984; Žutić and Legović, 1987; Marty et al., 1988; Svetličić et al., 2005, 2006; Žutić et al., 2004); (iv) transparent exopolymeric particles $(3-100 \mu \mathrm{m})$ detected by Alcian blue 
staining or spectrophotometrically (Alldredge et al., 1993; Schuster and Herndl, 1995; Passow, 2002; Radić et al., 2005; Villacorte et al., 2015a); and (v) protein-containing particles (2-500 $\mu \mathrm{m})$ visualized by Coomassie blue staining (Long and Azam, 1996).

While relatively broad scientific literature is available on the application of different techniques for characterization of marine organic matter, most of the methods include relatively expensive equipment and/or complex sample preparation procedures that effect the state of the fragile fractions of organic matter. It is now generally agreed that organic matter of a given chemical composition can occur in a large range of forms under the influence of dynamic aquatic conditions: monomer molecules, polymer chains, globules, vesicles and complex networks such as gels (Žutić and Svetličić, 2000). All of these will undoubtedly affect organic matter's persistence, stability, aggregation behaviour and bioavailability. Little is known about the distribution of environmental particles due not only to the difficulties in sampling, sample handling, insufficient sensitivity and selectivity of analytical methods but also to the heterogeneity of natural samples (Buffle and van Leeuwen, 1992). For example, the seawater sample needs to be unperturbed in order to preserve the heterogeneous distribution and primary structure of organic particles. High heterogeneity makes both the analysis and data interpretation challenging. Therefore, both development of methodological approaches and additional scientific understanding for assessing the environmental status of seawater are required. The aim of this overview is to emphasize advantages of a combined methodological approach applied to investigating hazardous situations in the Adriatic Sea, such as monitoring the first aggregation phases of dissolved organic matter in order to potentially predict the massive mucilage formation and testing of oil spill cleanup. Surface analytical methods, namely chronoamperometry at the dropping mercury electrode (DME) and atomic force microscopy (AFM), applied to monitor organic matter dynamics and oil pollution in the marine environment are based on fast, direct characterization and visualization from micro- to nanometre scale. We underline the importance that sample pretreatment is not required in order to capture the physical structure and organization of organic matter as closely as it exists in the natural system. Often, sample pretreatments such as filtration, centrifugation, staining and/or fixation introduce artefacts. The electrochemical approach is quickly compared to other methods, with sample characterization taking only a couple of minutes, making it suitable for analysis of a large number of natural seawater samples and thus applicable for monitoring purposes. In contrast, AFM can be applied to reveal structural organization of organic matter on the molecular level and to obtain three-dimensional (3-D) images of fine, fragile and soft structures. These data can be correlated to the electrochemical ones in order to shed more light on the biotic and abiotic transformations of organic matter at microand nanoscales (Ciglenečki and Svetličić, 2015). The advent of AFM introduced the possibility to directly explore these processes at a scale that determines the fate of organic matter and its interactions at the interfaces.

\section{Surface analytical methods for characterization of marine organic matter}

\subsection{Electrochemical method}

The electrochemical method used here is chronoamperometry of dissolved oxygen at a charged DME (Barradas and Kimmerle, 1966; Zvonarić et al., 1973). Chronoamperometry at a mercury electrode is an important and convenient tool for the in situ single particle analysis in an aqueous electrolyte solution. Mercury, as a liquid substrate, has several very unique advantages: it is atomically smooth, fluid and chemically inert with a large set of interfacial data in various aqueous electrolyte solutions, necessary for the analysis of the amperometric signal of an organic particle. Fluidity of mercury perfectly mimics interactions with other fluid interfaces in contact (e.g. biological membranes, vesicles, bubbles). Electrochemical measurement is performed by immersing the DME directly into the electrochemical vessel containing a fresh seawater aliquot of $15 \mathrm{~mL}$. The mercury electrode has a surface area of only $4.7 \mathrm{~mm}^{2}$ with drop lifetime of $2 \mathrm{~s}$. Every $2 \mathrm{~s}$, a new and reproducible mercury surface is formed at the end of the glass capillary and the analysis can be repeated many times. This is an important aspect of the method, since the arrival of particles to the interface is a stochastic process and the representative behaviour can be determined only by analysing a larger set of data collected under identical experimental conditions (Kovač et al., 2000). The electrochemical method is based on the sensing of the interfacial properties, hydrophobicity and supramolecular organization of particles rather than on the chemical composition (Žutić et al., 2004). The main advantage of the electrochemical approach is simultaneous and direct detection of different organic constituents in seawater based on their different electrochemical responses (Fig. 2) while inorganic particles remain undetected (Ivošević and Žutić, 1997; Baldi et al., 1999; Kovač et al., 1999; Svetličić et al., 2006; Ivošević DeNardis et al., 2007a). Organic constituents of seawater can be classified according to their electrochemical responses at the DME based on the molecular adsorption, adhesion and spreading, and particle collision (Žutić et al., 1990, 1993; Tsekov et al., 1999; Svetličić et al., 2006). On the chronoamperometric curve, adsorption of dissolved organic matter and submicron particles is manifested cumulatively as a gradual decrease of reduction current which is proportional to surfactant concentration in the sample, known as surfactant activity (Zvonarić et al., 1973; Žutić et al., 1977, 1999). Surfactant activity of seawater is expressed as the equivalent amount of the nonionic synthetic surfactant Triton-X-100 (polyethylene glycol tert-octylphenyl ether, $\mathrm{MW}=600$ ) in milligrams per litre. The polarographic maximum of $\mathrm{Hg}(\mathrm{II})$ ions offers 
an alternative approach to measuring dissolved organic carbon of seawater (Hunter and Liss, 1981). However, adhesion of fluid SAP with hydrophobic properties is detected on the single particle level through spike-shaped signal ( $\breve{u}$ tić et al. 1993; Svetličić et al., 2001; Ivošević DeNardis et al., 2007b). Collision of gel microparticle with the flexible three-dimensional network, thus possessing a hydrophilic character, is detected also on the single particle level through specific dip-shaped signal (Svetličić et al., 2006; Ivošević DeNardis et al., 2007a). The dropping mercury electrode as an in situ sensor enables characterization of fluid SAP in the aqueous environment (Žutić et al., 1984, 2004; Žutić and Legović, 1987) in terms of concentration, size, reactivity and hydrophobicity (Žutić et al., 1993; Kovač et al., 2000; Ivošević DeNardis et al., 2007b). Figure 3 shows the attractive interaction between an oil droplet and the charged electrode-seawater interface. Oil droplets, as a subclass of surface-active particles, adhere and spread at the charged interface, causing double layer charge displacement and establishment of the flow of the compensating current known as adhesion signals. Signal amplitude reflects the particle size, signal shape reflects the physicochemical properties of the particle and signal frequency indicates particle concentration in the seawater sample. Signal frequency is translated into particle concentration using the corresponding calibration curve with Dunaliella tertiolecta cells as standard particles (Kovač et al., 2000). Chronoamperometric measurements meet the requirements for monitoring based on the following advantages: (i) simple and fast analysis (100 s per sample) of soft micrometre particles in the size and concentration ranges of $1-500 \mu \mathrm{m}$ and $10^{5}-10^{8}$ particles $\mathrm{L}^{-1}$, respectively, and (ii) neither sample pretreatment nor sample fixation. Measurements on land were done within $24 \mathrm{~h}$ after sampling in the laboratory. Previous mesocosm experiments in seawaters show a major difference in the transformation of the surface-active matter not on the timescale of hours but rather on the seasonal level (Žutić et al., 2004).

In order to access more quantitative information from the amperometric signal of an organic particle, the measurement has to be performed in a previously deaerated solution under nitrogen purging for a few minutes so as to remove redox reaction of dissolved oxygen. In this way, it is possible to retrieve information about: organic particle diameter, particle surface area at the interface, number of molecules in the monolayer, surface charge of the particle, critical interfacial tensions of adhesion and kinetic parameters of the adhesion process through analysis of the amperometric signal using a reaction kinetics model and the corresponding methodology (Ivošević DeNardis et al., 2012, 2015).

\subsection{Atomic force microscopy}

AFM is based on a relatively simple principle: it involves raster scanning of a sharp and hard tip (probe) located at the free end of a flexible cantilever. The tip is scanned over the
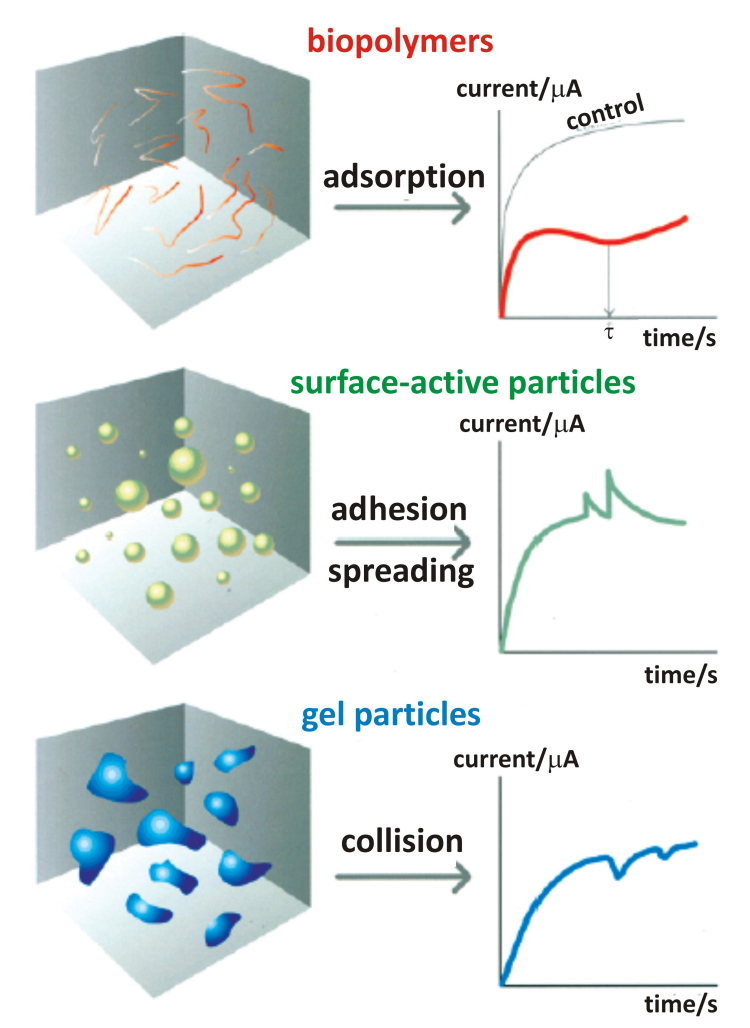

Figure 2. Illustration of different classes of organic constituents in seawater and their electrochemical signals at the electrode: biopolymer and small colloids, surface-active particles and gel particles (adapted from Svetličić et al., 2006).

surface of a sample, sensing the interaction forces between the tip and sample (Fig. 4). The sample is mounted on a piezoelectric scanner, which allows three-dimensional positioning with subnanometre accuracy. Interaction between the tip and the surface of the sample leads to cantilever bending, which is measured by laser light reflected from the cantilever to a position sensitive photodetector. As changes in cantilever deflection result in variation of the distance between the tip and sample, a constant distance is re-established with a feedback loop between the sample-tip positioning system and a computer-controlled piezoelectric scanner. Registered values of cantilever deflection are electronically converted into a pseudo 3-D image of the sample. As a result, AFM gives real 3-D images of the sample with a vertical resolution of $0.1 \mathrm{~nm}$ and lateral resolution of $1 \mathrm{~nm}$. The main advantages of AFM over conventional light or electron microscopy in studies of marine organic matter include (i) 3-D high-resolution imaging of different seawater constituents (biotic and abiotic) connecting micrometric and nanometric dimensions; (ii) samples being non-destructively imaged in the air and under near-natural aqueous conditions; (iii) nanomechanical mapping (i.e. Young's modulus, deformation, hydrophobicity, adhesion); and (iv) determination of intra- and inter- 


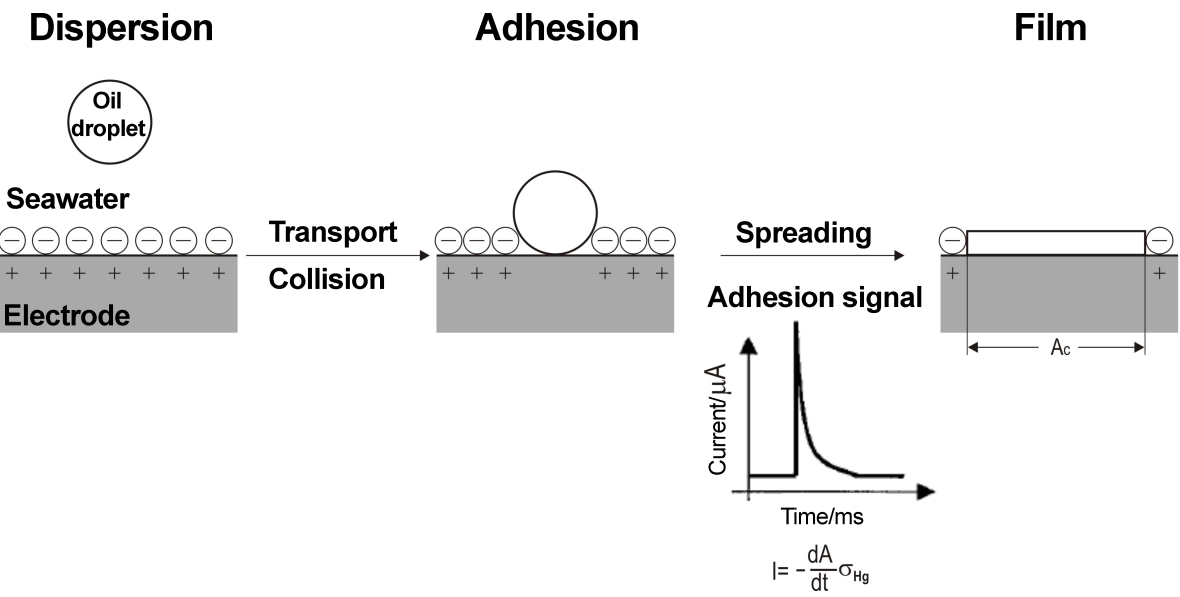

Figure 3. Basic principle of electrochemical adhesion-based detection: interaction of oil droplet with the charged electrode interface (adopted from Svetličić et al., 2001).

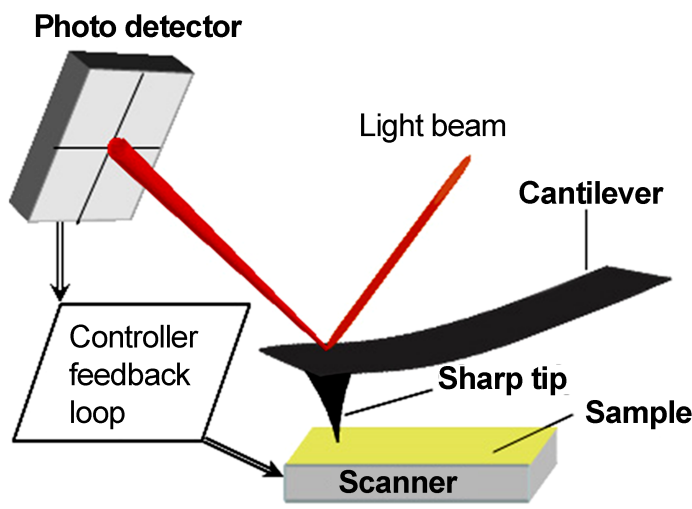

Figure 4. Basic principle of atomic force microscopy.

molecular forces in heterogeneous molecular assemblies (i.e. Pletikapić et al., 2014).

\section{Monitoring of organic matter dynamics in seawater}

\subsection{Electrochemical characterization of organic constituents in seawater}

After a dramatic mucilage event in the northern Adriatic in the summer of 1997, which had negative impact on the fishery and tourism, the monitoring programme "Systematic Study of the Adriatic Sea as a Base for Sustainable Development of the Republic of Croatia" was launched in 1998. Monitoring of organic matter dynamics was carried out to examine the environmental status in the northern Adriatic and to predict mucilage event. We focus on naturally occurring, non-living and micrometre-sized surface-active particles. This fraction mainly involves soft, hydrophobic, hydrophilic and reactive particles susceptible to degradation. Surface-active particles are described as vesicle or micelle- like structures formed by self-assembly of organic matter, primarily of lipid, polysaccharide and proteinaceous components deriving "mostly" from excreted cells and/or from their decomposed products (Žutić and Svetličić, 2000). They have an affinity to accumulate at the interfaces, and they can be measured directly electrochemically on the single particle level based on their interfacial properties, structural organization and hydrophobic-hydrophilic character. We introduced a direct electrochemical method to probe the state of marine organic matter without perturbing its original heterogeneous distribution. Figure 5 shows distribution of SAP (hydrophobic), gel microparticles (GeP) (hydrophilic) and surfactant activity measured over a period of 10 years at sampling station SJ 105. This particular sampling station was selected because it is distant from the coastline and thus the influence of direct input of inland freshwater is minimized (Fig. 1b). SAP concentrations ranged from $5 \times 10^{5}$ to $6 \times 10^{6} \mathrm{~L}^{-1}$ showing spatiotemporal variability with special patterns, which depends on the sampling depth in the water column and/or season. For example, significantly (about 2 times) higher SAP concentrations occurred in the region under the direct influence of nutrient-rich freshwater inputs of the Po River (SJ 101, 103, 108). In the first 3-year period $(2002,2003$, 2004), a mucilage event appeared. In the period just before the mucilage event, SAP concentration rose to $1 \times 10^{7} \mathrm{~L}^{-1}$ in the subsurface layer $(0-10 \mathrm{~m}$, SJ 101, 103, 108), indicating the forthcoming event (Svetličić et al., 2005). In contrast, low concentration of SAP in the subsurface layer at station SJ105 in 2007 is in line with the absence of mucilage events. Hence, SAP was identified and considered as a reactive mucilage precursor in seawater. Concentrations of $\mathrm{GeP}$ were usually around $10^{5} \mathrm{~L}^{-1}$ in the years without mucilage events $\left(0.2 \times 10^{5} \mathrm{~L}^{-1}\right.$ is the lower electrochemical detection limit). An elevated concentration of GeP, by about 1 order of magnitude $\left(15 \times 10^{6} \mathrm{~L}^{-1}\right)$, was determined in all sampling stations at the time of mucilage events (2002-2004). Surfac- 

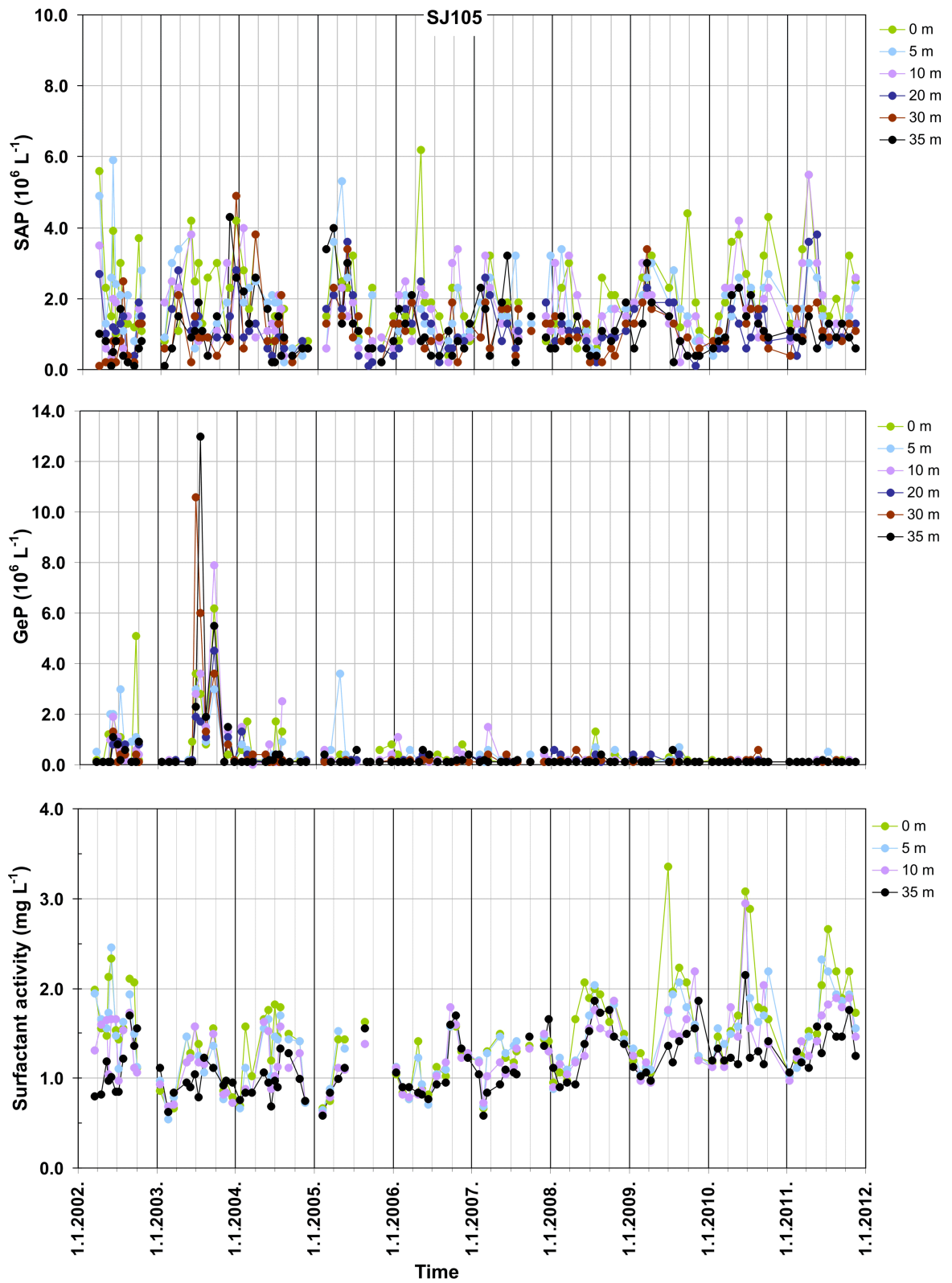

Figure 5. Annual variation of concentrations of surface-active particles (SAP), gel microparticles (GeP) and surfactant activity determined by electrochemical analysis of natural seawater samples taken at sampling station SJ 105 in the northern Adriatic.

tant activity reflecting the concentration of submicron and dissolved organic fractions varied from 0.5 to $2 \mathrm{mg} \mathrm{L}^{-1}$ in the years without mucilage events and decreased with the depth profile. Elevated surfactant activity up to $3.4 \mathrm{mg} \mathrm{L}^{-1}$ was determined during the mucilage event. In addition, a net increase of surfactant activity in the whole water column was observed at the end of years without mucilage events as a consequence of prolonged accumulation of organic matter in the water column (unpublished results). It was therefore concluded that the likelihood of mucilage formation depends mainly on new primary production, specific structural orga- nization of the newly produced organic matter and, above all, hydrographic and meteorological conditions in the seawater.

\subsection{AFM imaging of marine organic matter at the nanometric scale}

AFM as a high-resolution imaging technique that requires only easy sample preparation has a huge potential in investigating marine organic matter, particularly in elucidating the structure, transformations and dynamics of organic matter in the marine environment. Of all forms of organic matter, marine fibrils and fibrillar networks were the most studied form. 

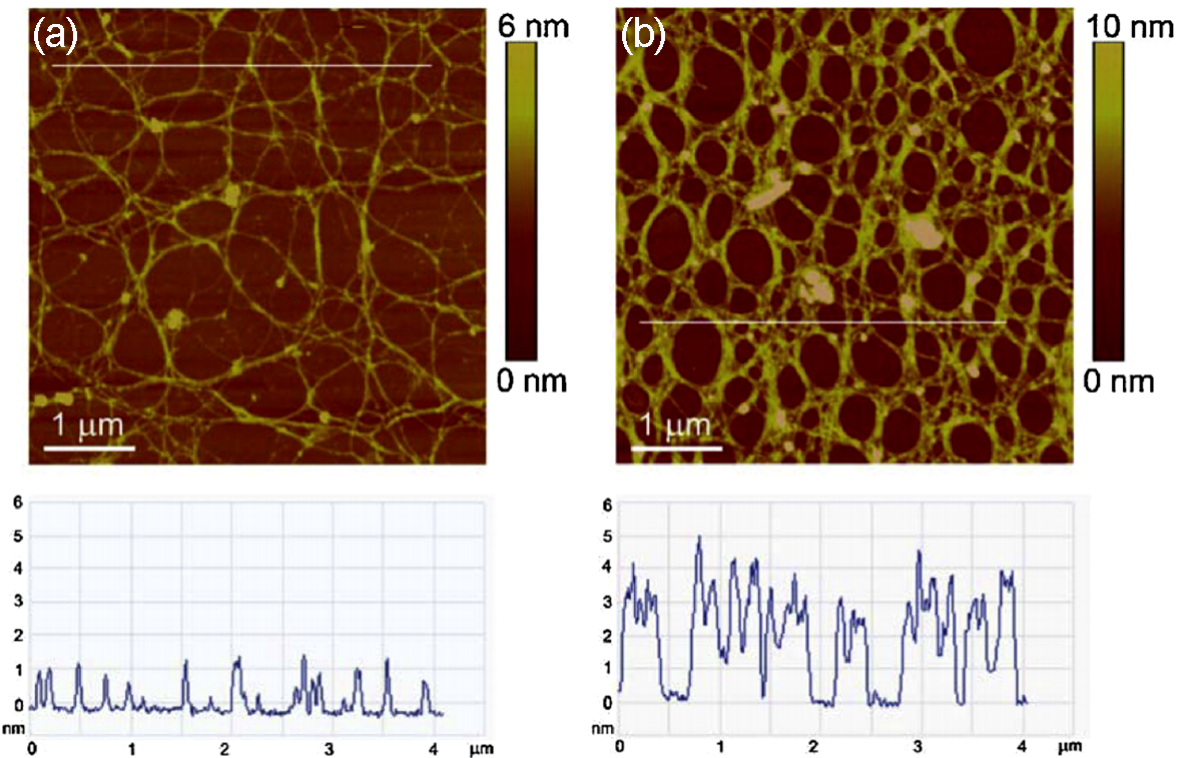

Figure 6. AFM topographic images of marine gel representing networks with (a) a low degree of fibril cross-linking and (b) a high degree of cross-linking with the corresponding cross sections along the indicated lines. Marine gel samples were collected in the northern Adriatic (SJ 105) in 23 June 2003, at a depth of 10-13 m (Mišić Radić et al., 2011).

For example, Santschi et al. (1998) were the first to image individual fibrillar polysaccharides in marine macromolecular organic matter. From there on, AFM has been applied to study both (i) the networks secreted by marine bacteria and algae (Nishino et al., 2004; Svetličić et al., 2005, 2013; Malfatti and Azam, 2009; Malfatti et al., 2010; Urbani et al., 2012; Bosak et al., 2012; Villacorte et al., 2015b) and (ii) marine fibrils (Mišić Radić et al., 2011; Svetličić et al., 2011) forming giant gel macroaggregates (Vollenweider and Rinaldi, 1999; Giani et al., 2005a, b), including their selfassembly and molecular structure at different levels of association (Mišić Radić et al., 2011; Pletikapić et al., 2014). Application of AFM imaging for monitoring by itself is often not suitable. This is due to the large number of samples required in the monitoring studies, making AFM analysis, if used alone, a time-consuming process. It is therefore recommended to analyse seawater samples first with rapid and "bulk" techniques (i.e. chronoamperometry) in order to identify samples of interest. For AFM imaging, the drop deposition method modified for marine samples and imaging in air was found to be most adequate for visualization of macromolecular organic matter organization (Pletikapić et al., 2011; Mišić Radić et al., 2011, for more detail). Typically, AFM measurements of marine organic samples are performed at room temperature and $50-60 \%$ of relative humidity, which leaves samples with a small hydration layer adhering to the substrate, helping to maintain the native structure (Balnois and Wilkinson, 2002). It was found that direct deposition of a drop of seawater $(5 \mu \mathrm{L})$ on freshly cleaved mica, followed by the rinsing of sea salts and evaporation of water excess, was the procedure that caused the least impact on the original structures of biopolymers and other assemblies in seawater (Mišić Radić, 2011; Svetličić et al., 2013). Such an approach could offer an alternative way to visualize fragile organic structures. Although an aqueous environment would be preferable, direct AFM imaging of marine polymers, soft vesicular structures and organic droplets is often hampered by their weak interaction with the interface. While interpreting the data, one should consider possible surface and/or dehydration artefacts. Representative images of marine fibril forming networks with different levels of biopolymer entanglements and with different pore sizes are shown in Fig. 6. It is interesting to note that the appearance of marine gel networks at the nanometric scale, as shown in the corresponding figure, coincided with the occurrence of gel microparticles detected electrochemically at the same sample, as shown in Fig. 5. Image analysis revealed that biopolymer heights were in the $0.5-2.5 \mathrm{~nm}$ range, while pore sizes ranged from $\sim 40 \mathrm{~nm}$ to more than $1 \mu \mathrm{m}$ along the longest axis. Svetličić et al. (2011) found that these parameters (pore size, fibril height) can be related to the aging of gel aggregates in the water column; i.e. older aggregates contained smaller pores and thicker fibrils, while "young" aggregates had a looser structure with smaller fibrils and bigger pore sizes. One of the most comprehensive chemical characterization studies of northern Adriatic gel macroaggregates showed that carbohydrates are the main organic fraction and that the average ratio of polysaccharides to total organic carbon is $41.5 \%$ (Giani et al., 2005b). Exopolysaccharides released by the diatom Cylindrotheca closterium under the conditions of increased production comprised a simpler system, which had the same chemical composition of polysaccharides as marine 
gels, indicating that the diatom exopolymeric substance was the most likely origin of marine gels (Urbani et al., 2005). In addition, a striking similarity was found in both marine gels and reconstituted polysaccharide networks (obtained from the same diatom) in terms of their mechanical properties as well as morphological features (Pletikapić et al., 2014). Marine gels were characterized in the non-imaging mode of AFM, the so-called "fishing", where single polymers and/or their more complex associations are "picked up from the surface (fished) by the AFM probe and extended and/or unfolded/unzipped by increasing the distance of the AFM tip from the surface. This approach enabled relating mechanical properties to different biopolymer morphologies (from single fibril, helical structures to more complex junction zones in networks with a higher degree of cross-linking), revealing new information about network architecture and connectivity. As native marine gels are constantly exposed to mechanical perturbations caused by local hydrodynamics (turbulence and shear) as well as large-scale physical processes (strong winds and currents), the application of hundreds of piconewtons of force is highly biologically relevant. Networks were characterized as physical gels in line with DCS measurements (Mišić et al., 2011), where the level of association can be controlled by dilution, adjusting the ionic strength and stirring (Pletikapić et al., 2014). Marine gels are defined as three-dimensional networks of solvated biopolymers embedded in seawater. Their importance in marine ecosystems has been widely recognized among scientists from different fields due to their role in the microbial loop and sedimentation processes, biogeochemical carbon cycling, marine carbohydrate chemistry and particle dynamics in the ocean (Žutić and Svetličić, 2000; Azam and Long, 2000; Passow, 2002; Verdugo et al., 2004; Verdugo, 2012). These gels are also bioreactive since they compartmentalize nutrients and can thus enhance microbial activity (Kepkay, 1994; Azam, 1998, Del Negro et al., 2005). Due to their dense 3-D network structure and "sticky" nature, marine gels show a potential to scavenge nanoparticles that accumulate in the junction zones of the network (Svetličić et al., 2011; Pletikapić et al., 2012b). In this way, marine gels might stabilize nanoparticles and prevent aggregation and export from the water column. Recent review highlights the potential of AFM in revealing new information about the interaction of inorganic nanoparticles with living and non-living organic matter (Ciglenečki and Svetličić, 2015; Wang et al., 2016).

In addition, gel network formation was visualized at station SJ 107 in August 2010, when concentrations of micrometre-sized GeP and SAP were low (0.2 and $2.3 \times 10^{6} \mathrm{~L}^{-1}$, respectively). Significantly higher concentration of submicron organic content (surfactant activity, $2.88 \mathrm{mg} \mathrm{L}^{-1}$ ) was detected 2 months prior to the mucilage event at the depth of $10 \mathrm{~m}$, in 2010, which could act as a pool for biopolymer self-organization into marine vesicles that under specific conditions transform to giant gel (Svetličić et al., 2005). For identification of vesicle-like structures, AFM can be a very suitable tool due to the high-resolution imaging and easy sample preparation. The existence of marine vesicles has already been inferred by Žutić et al. (1984) and later by Nagata and Kirchman (1997). Recently, it was reported that membrane vesicles of $100 \mathrm{~nm}$ in diameter can be released by marine cyanobacteria and are frequently found in marine ecosystems in the concentration range $10^{5}$ to $10^{6}$ vesicles $\mathrm{mL}^{-1}$ (Soler et al., 2015). Such vesicles may entrap nutrients, toxins and a variety of other organic molecular species present in seawater. These components may be concentrated and preserved from degradation in the inner cavity of the vesicle and/or attached to the membrane of the vesicle. This ability of vesicles to transport and deliver diverse compounds in discrete packages adds another layer of complexity to the flow of information, energy and biomolecules in marine microbial communities (Biller et al., 2014). Such vesicles (Fig. 7) were also periodically encountered during the diatom bloom experiment and during the northern Adriatic field studies by AFM (Žutić et al., 2004; Svetličić et al., 2008). It is likely that the abundance of such structures is highly underestimated. Due to the small size and relatively soft and fragile character of these structures, during AFM imaging with relatively higher forces, particularly when contact mode is used, vesicles are swept away by the AFM tip and remain undetermined. Proper care while setting imaging parameters, scanning at low force (i.e. peak force tapping mode) and coupling AFM with other bulk methods such as electrochemistry to identify the sample of interest with higher concentrations of vesicles may resolve the issue. Such an approach was used to study vesicle-like particles in the Bay of Kotor (Ivošević DeNardis et al., 2013, 2014). The most important findings show that both surface analytical methods, electrochemical and AFM, provide comparable results on different scales.

However, despite this, AFM is not yet exploited up to its full potential. Significant advances in the field are expected by integrating AFM into versatile hybrid devices that would combine two or three complementary techniques in one instrument, allowing a more detailed and comprehensive analysis of marine samples. While simultaneous AFM imaging and mechanical mapping (stiffness, friction, dissipation and/or adhesion) is already showing its potential by increasing the number of studies conducted on biological samples (Dufrêne et al., 2013, and references therein), including marine samples (Francius et al., 2008; Pletikapić et al., 2012a), of particular interest for investigation of marine organic matter is coupling AFM with different optical, spectroscopic and/or interfacial techniques (Moreno and TocaHerrera, 2009). In line with the topic covered in this paper, integration of mercury as a substrate in the AFM setup is drawing particular attention (Schon et al., 2013). An AFM cantilever has been developed using a mercury fountain pen probe allowing simultaneous probing of mechanical and electrical properties, for instance in biological membrane research. In addition, a hybrid AFM-optical (fluores- 


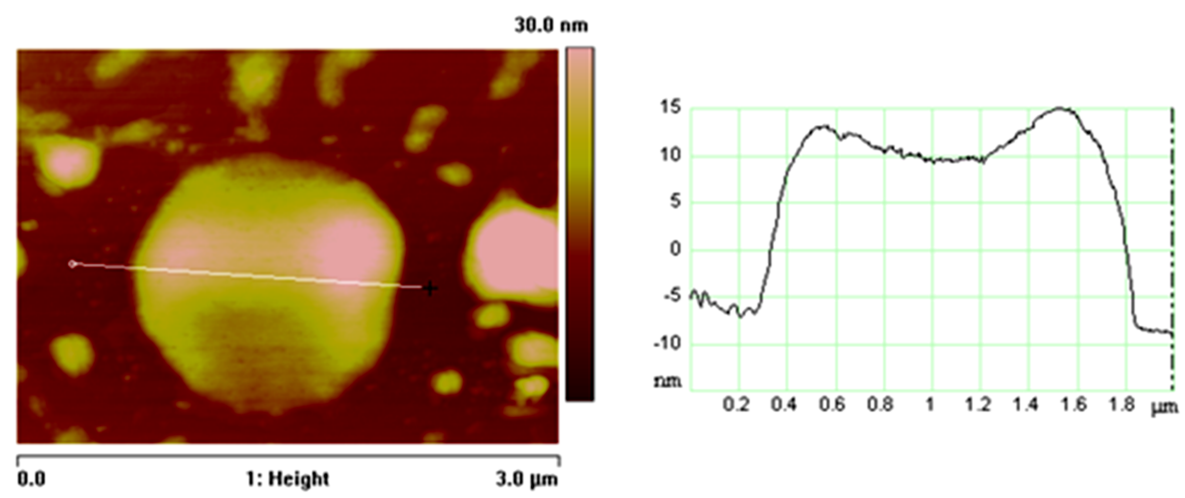

Figure 7. Large marine vesicle of $1.5 \mu \mathrm{m}$ diameter imaged by AFM with the corresponding cross section along the indicated line. Samples were collected in the northern Adriatic (SJ 101) in 18 May 2010, at a depth of $0 \mathrm{~m}$.

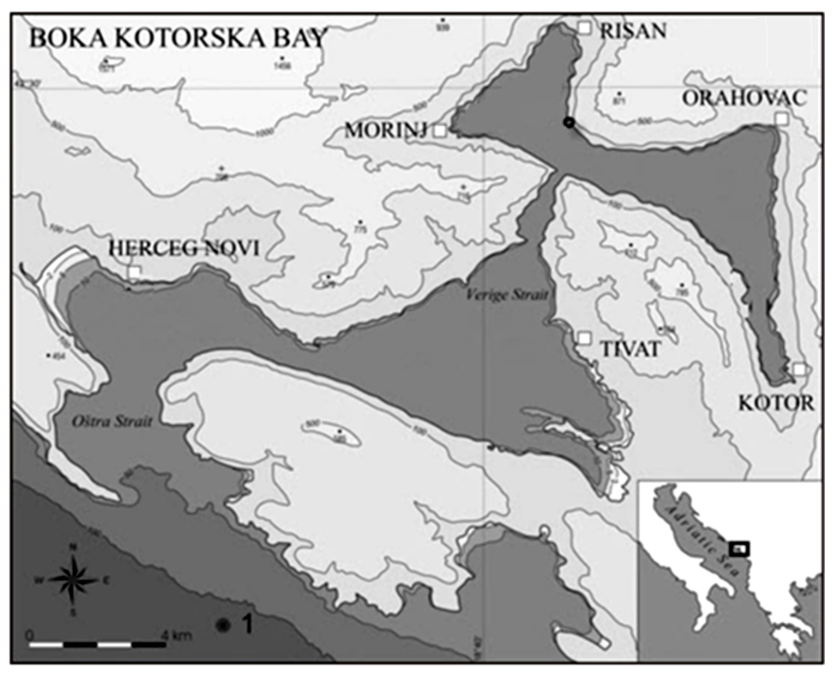

Figure 8. Sampling station of Rt Murva (•) in the Bay of Kotor (Montenegro; inset: study area, southern Adriatic Sea, adopted from Ivošević DeNardis et al., 2014).

cence) microscope (Kassies et al., 2005; Geisse et al., 2009) would be extremely useful for deepening the research on different classes of organic particles traditionally detected by staining and microscopic analysis. An additional step forward in the field is expected by combining AFM and IR to provide simultaneous correlation of topographical (organizational) and chemical data (Dazzi et al., 2012; Amenabar et al., 2013; Kulik et al., 2014). Alternatively, one could use chemically functionalized tips and, by simultaneously performing imaging and force curve acquisition, generate chemical maps (Blanchette et al., 2008). Such studies would allow relating molecular organization of marine organic matter with chemical information on the micro- and nanometre scales, which would undoubtedly widen the spectrum of information about samples of interest.

\section{Monitoring of oil pollution in seawater}

Surface analytical methods can also be applied for testing of the environmental status of seawater after oil spill cleanup. We detected, characterized and visualized the presence of dispersed oil droplets in the seawater due to the accidental sinking of a ship and oil spill in the Bay of Kotor (south Adriatic sea, Montenegro). The ship sank on 11 October 2013 at Rt Murva (15 m depth) in the Bay of Kotor (Fig. 8; Ivošević DeNardis et al., 2014). The ship had an overall length of $32.7 \mathrm{~m}$ and weighed 325 tons, carrying oil and diesel oil (type D2). One month after the mechanical removal of oil spill, dispersed oil droplets were still present in the whole water column. Characterized oil droplets were in the continuum size range from micro to nano. Smaller oil droplets tend to accumulate at the halocline, while larger rise to the surface where they may coalesce. The highest droplet concentration of $2.0 \times 10^{5} \mathrm{~L}^{-1}$ was determined at the $5 \mathrm{~m}$ depth (i.e. at the density gradient), while at the other depths the concentration of droplet was bellow detection limit for electrochemical detection. Dispersed droplets were in the size range from $1 \mu \mathrm{m}$ up to $30 \mu \mathrm{m}$ in measured samples (determined by microscopy and Nile red staining). Bacterial colonization of micrometresized fuel droplets indicated that a biodegradation process occurred, as revealed by epifluorescence microscopy and DAPI staining (Fig. 9a). Hydrocarbon-degrading bacteria could account for up to $10 \%$ of the total bacterial population (Hassanshahian and Cappello, 2013), and thus the biodegradation process is rather slow. Hydrocarbon-degrading bacteria utilize oil droplets as a carbon and energy source. Bacterial efficiency in the degradation of diesel fuel droplets can be measured as a change in droplet concentration, distribution, size, bacterial film formation and bacterial oxygen consumption and through chemical changes of oil composition (Baldi et al., 1997, 1999). AFM could be of particular importance in imaging interactions between bacteria and oil droplets on the micro- and nanometre scale, which would enable better understanding of the mechanism of biofilm forma- 

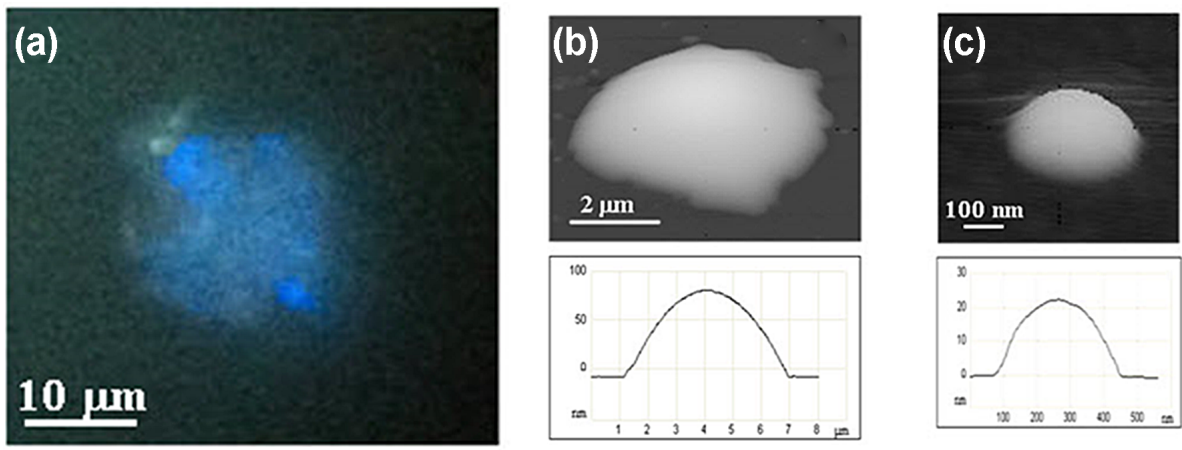

Figure 9. (a) Dispersed fuel oil droplets observed under an optical microscope with DAPI staining; (b) three-dimensional views of typical nanometre-sized fuel oil droplets in the natural seawater sample taken at the Rt Murva depth of $0 \mathrm{~m}$; (c) depth of $5 \mathrm{~m}$ visualized by AFM with the corresponding vertical profiles. Vertical profile enables to calculate oil droplet diameter in seawater (adopted from Ivošević DeNardis et al., 2014).

tion and therefore provide an insight into the efficiency of the biodegradation process. In addition, force spectroscopy can be applied to probe the adhesion force between the bacterial cell and the droplet and to measure nanomechanical properties of both the bacterial cell and oil droplets. Moreover, AFM can provide an insight into the nanoscale surface morphology of biofilms or aggregates. AFM images of larger and smaller nanometre-sized oil droplets spread over the mica substrate forming spherical caps are shown in Fig. 9b and c. The imaged droplet diameter in seawater would correspond to 520 and $80 \mathrm{~nm}$, respectively (Ivošević DeNardis et al., 2014). Nanometre-sized droplets were detected in the whole water column as reactive and stable fractions that persist longer and can therefore cause a significant decrease of phytoplankton primary production. Recovery of phytoplankton variability and abundance after a heavy fuel oil spill in the Marmara Sea, Turkey, required a time period of 3 years (Tas and Erdogan, 2007). The consequences of anthropogenically caused oil spills are known to provoke serious ecosystem disturbances influencing the variability in planktonic dynamics, survival of fish eggs, larvae, shellfish, hatching, swimming activity, fertility in copepods and overall tropic interactions. For example, dispersed diesel oil had a harmful effect on the cardiac activity of Mediterranean mussels (Bakhmet et al., 2009; Martinović et al., 2015) important for adequate protection of shellfish farms, breeding control and preventing food poisoning of humans. Bay of Kotor is a semi-closed basin of Montenegro characterized by Karst rivers and underground springs, which affect the temperature, density and salinity of seawater (Campanelli et al., 2009). To understand the fate and behaviour of dispersed diesel fuel under the complex hydrodynamic conditions requires a comprehensive and interdisciplinary approach. Supplementary modelling data of the corresponding geographical area would be of benefit in order to assess the scale of oil spreading and trajectory, important for emergency responses and decision matters. Such an approach can help understand the scale of the problem and efficient coordination between local authorities, research and industry in order to enable environmental protection as well as sustainable development.

\section{Conclusions}

Surface analytical methods are applied for hazardous situation in the Adriatic Sea such as monitoring the first aggregation phases of dissolved organic matter in order to potentially predict the massive mucilage formation and testing of oil spill cleanup. The monitoring study conducted in the northern Adriatic enabled investigation of the environmental status of seawaters based on the spatiotemporal distribution of organic matter. A few months prior to the mucilage event, promoted by certain meteorological and hydrodynamics conditions, the concentration of accumulated SAP in the halocline reached $1 \times 10^{7} \mathrm{~L}^{-1}$, and a large-scale sol-gel organic matter phase transformation occurred. Surface-active particles were therefore identified as reactive mucilage precursors in seawater. Formation of a gel network at the nanometric scale coincided with elevated concentrations of flexible GeP or surfactant activity prior and after the macroaggregation event. In the second example, in spite of the mechanical removal of the main oil spill content, the remaining invisible but reactive micro- and nanodroplets were detected in the collected sample. Revealed persistence of oil droplets in the water column poses a serious threat to plankton community, nearby mussel farms, fisheries and tourism. Such a methodological approach may contribute to optimizing clean up performance after accidental events. Monitoring of the environmental status of seawaters should be recommended due to the intensive boat trafficking and shipyard activity in the Bay of Kotor in order to decrease the risk to the sensitive marine ecosystem. Interdisciplinary approach and long-term measurements of relevant parameters are required in order to better understand the spatiotemporal distribution of organic matter in aquatic systems and consequently its 
role in the biogeochemical cycles. In the future, we foresee that integration of experimental data (on nanometre and micrometre scales) with mathematical models (on the kilometre scale), taking into account meteorological data, oceanographic conditions, circulation pattern and satellite data, will contribute to a better understanding of organic matter dynamics in aquatic systems through development of sophisticated technological platform for knowledge transfer, reports and maps applicable for the marine environmental protection and management of the coastal area, especially for tourism, fishery and cruiser trafficking.

\section{Data availability}

Corresponding data sets referring to this paper can be accessed upon request to authors.

Acknowledgements. This work was supported by the Croatian Ministry of Science, Education and Sports through the projects (i) Surface Forces on Atomic Scale Applied in Marine Science and Nanotechnology, (ii) National Monitoring Programme (Project Jadran), Systematic Research of the Adriatic Sea as a Base for Sustainable Development of the Republic of Croatia, and (iii) Croatia-Montenegro bilateral scientific cooperation "Impact Assessment and Determination of Organic Pollutants in the Waters" (project leaders: Zoran Kljajić and NID). The authors thank V. Svetličić and V. Žutić for coordinating the organic microparticle study in the framework of Project Jadran. We thank many coworkers who contributed to the activities described in this paper. This review is dedicated to the memory of the late Zoran Kljajić of the Institute of Marine Biology, Kotor, Montenegro.

Edited by: A. Olita

Reviewed by: A. Podestà and M. G. Giani

\section{References}

Alldredge, A. L., Passow, U., and Logan, B. E.: The abundance and significance of a class of large, transparent organic particles in the ocean, Deep-Sea Res., 40, 1131-1140, doi:10.1016/09670637(93)90129-Q, 1993.

Amenabar, I., Poly, S., Nuansing, W., Hubrich, E. H., Govyadinov, A. A., Huth, F., Krutokhvostov, R., Zhang,L., Knez, M., Heberle, J., Bittner, A. M., and Hillenbrand, R.: Structural analysis and mapping of individual protein complexes by infrared nanospectroscopy, Nat. Comm., 4, 2890-2899, doi:10.1038/ncomms3890, 2013.

Azam, F.: Microbial control of oceanic carbon flux: The plot thickens, Science, 280, 694-696, doi:10.1126/science.280.5364.694, 1998.

Azam, F. and Long, A. R.: Sea snow microcosmos, Nature, 414, 495-498, doi:10.1038/35107174, 2000.

Bakhmet, I. N., Fokina, N. N., Nefedova, Z. A., and Nemova, N. N.: Physiological-biochemical properties of blue mussel Mytilus edulis adaptation to oil contamination, Environ. Monit. Assess., 155, 581-591, doi:10.1007/s10661-008-0457-5, 2009.
Baldi, F., Pepi, M., Fani, R., Di Cello, F., Da Ros, L., and Fossato, V. U.: Complementary degradation of fuel oil in superficial waters and in axenic cultures of aerobic Gram-negative bacteria isolated from Venice Lagoon, Croat. Chem. Acta, 70, 333-346, 1997.

Baldi, F., Ivošević, N., Minacci, A., Pepi, M., Fani, R., Svetličić, V., and Žutić, V.: Adhesion of Acinetobacter venetianus to diesel fuel droplets studied by in situ electrochemical and molecular probes, Appl. Environ. Microb., 65, 2041-2048, 1999.

Balnois, E. and Wilkinson, K. J.: Sample preparation techniques for the observation of environmental biopolymers by atomic force microscopy, Colloid Surface A, 207, 229-242, doi:10.1016/S0927-7757(02)00136-X, 2002.

Barradas, R. G. and Kimmerle, F. J.: Effect of highly surface-active compounds on polarographic electrode processes, J. Electroanal. Chem., 11, 163-170, doi:10.1016/0022-0728(66)80079-7, 1966.

Biller, S. J., Schubotz, F., Roggensack, S. E., Thompson, A. W., Summons, R. E., and Chisholm, S. W.: Bacterial vesicles in marine ecosystems, Science, 10, 183-186, doi:10.1126/science.1243457, 2014.

Blanchette, C. D., Timothy, A. L. and Ratto, V.: Tip functionalization: Applications to chemical force spectroscopy, in: Handbook of Molecular Force Spectroscopy, edited by: Noy, A., Springer International Publishing, the Netherlands, 185-203, 2008.

Bosak, S., Pletikapić, G., Hozić, A., Svetličić, V., Sarno, D., and Viličić, D.: A novel type of colony formation in marine planktonic diatoms revealed by atomic force microscopy, PLoS One, 7, e44851, doi:10.1371/journal.pone.0044851, 2012.

Buffle, J. and van Leeuwen, H. P.: Environmental particles, Lewis publishers, London, UK, 1992.

Campanelli, A., Bulatović, A., Cabrini, M., Grilli, F., Kljajić, Z., Mosetti, R., Paschini, E., Pierluigi, P., and Marini, M.: Spatial distribution of physical, chemical and biological oceanographic properties, Phytoplankton, nutrients and Coloured Dissolved Organic Matter (CDOM) in the Boka Kotorska Bay (Adriatic Sea), Geofizika, 26, 1-14, 2009.

Carlson, C. A.: Production and removal processes, in: Biogeochemistry of marine dissolved organic matter, edited by: Hansell, D. A. and Carlson, C. A., Academic Press, San Diego, CA, USA, 91-151, 2002.

Ciglenečki, I. and Svetličić, V.: Nanoparticles and Marine Environment: An Overview, in: Nanotechnology to Aid Chemical and Biological Defense, edited by: Camesano, T. A., Springer International Publishing, the Netherlands, 95-112, 2015.

Dazzi, A., Prater, C. B., Hu, Q., Chase, D. B., Rabolt, J. F., and Marcott C.: AFM-IR: combining atomic force microscopy and infrared spectroscopy for nanoscale chemical characterization, Appl. Spectrosc., 66, 1365-1384, doi:10.1366/12-06804, 2012.

Del Negro, P., Crevatin, E., Larato, C., Ferrari, C., Totti, C., Pompei, M., Giani, M., Berto, D., and Umani, S. F.: Mucilage microcosms, Sci. Total Environ., 353, 258-269, doi:10.1016/j.scitotenv.2005.09.018, 2005.

Dufrêne, Y. F., Martínez-Martín, Y. F., Medalsy, D., Alsteens, I., and Müller, D.: Multiparametric imaging of biological systems by force-distance curve-based AFM, Nat. Methods, 10, 847-854, doi:10.1038/nmeth.2602, 2013.

Fonda-Umani, S., Ghirardelli, E., Specchi, M.: Gli episodi di "mare sporco" nell'Adriatico dal 1729 ai giorni nostri. Regione Autonoma Friuli-Venezia Giulia, Direzione Regionale dell'Ambiente, Trieste, Italy, p. 178, 1989. 
Francius, G., Tesson, B., Dague, E., Martin-Jezequel, V., and Dufrene, Y. F.: Nanostructure and nanomechanics of live Phaeodactylum tricornutum morphotypes, Environ. Microbiol., 10, 1344-1356, doi:10.1111/j.1462-2920.2007.01551.x, 2008.

Geisse, N. A: AFM and combined optical techniques, Mater. Today, 12, 40-45, doi:10.1016/S1369-7021(09)70201-9, 2009.

Giani, M., Degobbis, D., and Rinaldi, A.: Mucilages in the Adriatic and Tyrrhenian seas, Sci. Total. Environ., 353, 1-380, doi:10.1016/j.scitotenv.2005.09.006, 2005a.

Giani, M., Berto, D., Zangrando, V., Castelli, S., Sist, P., and Urbani, R.: Chemical characterization of different typologies of mucilaginous aggregates in the Northern Adriatic Sea, Sci. Total. Environ., 353, 232-246, doi:10.1016/j.scitotenv.2005.09.027, 2005b.

Hassanshahian, M. and Cappello, S.: Crude oil Biodegradation in the marine environments in biodegradation-engineering and technology, edited by: Chamy, R. and Rosenkranz, F., InTech, Rijeka, Croatia, 101-135, doi:10.5772/55554, 2013.

Hunter, K. A. and Liss, P. S.: Polarographic measurement of surface-active material in natural waters, Water Res., 15, 203215, doi:10.1016/0043-1354(81)90113-5, 1981.

Ivošević, N. and Žutić, V.: Polarography of marine particles: A model study, Croat. Chem. Acta, 70, 167-178, 1997.

Ivošević DeNardis, N., Žutić, V., Svetličić, V., and Urbani, R.: In situ amperometric detection of vesicles and microgel phases in an aggregating system: Calcium Alginate, Electroanal., 19, 473478, doi:10.1002/elan.200603750, 2007a.

Ivošević DeNardis, N., Žutić, V., Svetličić, V., Frkanec, R., and Tomašić, J.: In situ amperometric characterization of liposome suspensions with concomitant oxygen reduction, Electroanal., 19, 2444-2450, doi:10.1002/elan.200703999, 2007 b.

Ivošević DeNardis, N., Ružić, I., Pečar Ilić, J., El Shawish, S., and Ziherl, P.: Reaction kinetics and mechanical models of liposome adhesion on charged interface, Bioelectrochemistry, 88, 48-56, doi:10.1016/j.bioelechem.2012.05.003, 2012.

Ivošević DeNardis, N., Šegota, S., Svetličić, V., Castelli, A., and Kljajić, Z.: Characterization of marine organic matter in the bay of the Boka Kotorska by electrochemical and atomic force microscopy imaging, Stud. Mar., 26, 5-22, 2013.

Ivošević DeNardis, N., Šegota, S., Svetličić, V., Pletikapić, G., and Kljajić, Z.: Presence of dispersed diesel fuel in water column in the Boka Kotorska bay: A case study, Stud. Mar., 27, 43-64, 2014.

Ivošević DeNardis, N., Pečar Ilić, J., Ružić, I., and Pletikapić, G.: Cell adhesion and spreading at a charged interface: Insight into the mechanism using surface techniques and mathematical modelling, Electrochim. Acta, 176, 743-754, doi:10.1016/j.electacta.2015.07.068, 2015.

Kassies, R., Van Der Werf, K. O., Lenferink A, Hunter, C. N., Olsen, J. D., Subramaniam, V., and Otto C.: Combined AFM and confocal fluorescence microscope for applications in bionanotechnology, J. Microsc., 217, 109-116, doi:10.1111/j.00222720.2005.01428.x, 2005.

Kepkay, P.: Particle aggregation and the biological reactivity of colloids, Mar. Ecol.-Prog. Ser., 109, 293-304, doi:10.3354/meps111293, 1994.

Koike, I., Hara, S., Terauchi, K., and Kogure, K.: Role of submirrometre particles in the ocean, Nature, 345, 242-244, doi: doi:10.1038/345242a0, 1990.
Kovač, S., Svetličić, V., and Žutić V.: Molecular adsorption vs. cell adhesion at an electrified aqueous interface, Colloid Surface A, 149, 481-489, doi:10.1016/S0927-7757(98)00519-6, 1999.

Kovač, S., Kraus, R., Geček, S., and Žutić, V.: Cell suspension as a model system for electrochemical analysis, Croat. Chem. Acta, 73, 279-291, 2000.

Kujawinski, E. B., Longnecker, K., Barott, K. L., Weber R. J. M., and Kido Soule M.C.: Microbial community structure affects marine dissolved organic matter composition, Front. Mar. Sci., 3, 1-15, doi:10.3389/fmars.2016.00045, 2016.

Kulik, A. J., Ruggeri, A. J, Wieslaw, F. S., Gruszecki, I., and Dietler, G.: Nanoscale infrared spectroscopy of light harvesting proteins, amyloid structures and collagen fibres, Microscopy and Analysis, 28, 11-14, 2014.

Leppard, G. G., West, M. M., Flannigan, D. T., Carson, J., and Lott, J. N. A.: A classification scheme for marine organic colloids in the Adriatic Sea: colloid speciation by transmission electron microscopy, Can. J. Fish. Sci., 54, 2334-2349, 10.1139/f97-140, 1997.

Long, R. A. and Azam, F.: Abundant protein-containing particles in the sea, Aquat. Microb. Ecol., 10, 213-221, doi:10/a010p213, 1996.

Longhurst, A. R., Koike, L., Li, W., Rodriguez, J., Dickie, P., Kepkay, P., Partensky, F., Bautista, B., Ruiz, J., Wells, M. L., and Bird, D.: Sub-micron particles in north-west Atlantic shelf water, Deep-Sea Res., Rapid Response Paper, 39, 1-7, 1992.

Malfatti, F. and Azam, F.: Atomic force microscopy reveals microscale networks and possible symbioses among pelagic marine bacteria, Aquat. Microb. Ecol., 58, 1-14, doi:10.3354/ame01355, 2009.

Malfatti, F., Samo, T. J., and Azam, F.: High-resolution imaging of pelagic bacteria by atomic force microscopy and implications for carbon cycling, ISME J., 4, 427-439, doi:10.1038/ismej.2009.116, 2010.

Martinović, R., Gačić, Z., and Kljajić, Z.: The Influence of oil, dispersed oil and the oil dispersant SD-25 on the heart rate of the Mediterranean mussel (M. galloprovincialis L.), in: Sustainable Development of Sea-Corridors and Coastal Waters, edited by: Stylios, C., Floqi, T., Martinski, J., and Damiani L., Springer International Publishing, Switzerland, 21-27, doi:10.1007/9783-319-11385-2_2, 2015.

Marty, J.-C., Žutić V., Precali R., Saliot A., Ćosović B., Smodlaka, N., and Cauwet, G.:Organic matter characterization in the Northern Adriatic Sea with special reference to the sea surface microlayer, Mar. Chem., 26, 313-330, doi:10.1016/03044203(89)90037-6, 1988.

Mišić Radić, T., Svetličić, V., Žutić, V., and Boulgaropoulos, B.: Seawater at the nanoscale: marine gels imaged by atomic force microscopy, J. Mol. Recognit., 24, 397-405, doi:10.1002/jmr.1072, 2011.

Mopper, K., Stubbins, A., Ritchie, J. D., Bialk, H. M., and Hatcher, P. G.: Advanced instrumental approaches for characterization of marine dissolved organic matter: extraction techniques, mass spectrometry, and nuclear magnetic resonance spectroscopy, Chem. Rev., 107, 419-442, 2007.

Moreno F. S. and Toca-Herrera, J. L.: The new future of scanning probe microscopy: Combining atomic force microscopy with other surface-sensitive techniques, optical mi- 
croscopy and fluorescence techniques, Nanoscale, 1, 40-49, doi:10.1039/b9nr00156e, 2009.

Nagata, T. and Kirchman, D. L.: Roles of submicron particles and colloids in microbial food webs and biogeochemical cycles within marine environments, Adv. Mar. Biol., 15, 81-103, 1997.

Nebbioso, A. and Piccolo, A.: Molecular characterization of dissolved organic matter (DOM): a critical review, Anal. Bioanal. Chem., 405, 109-124, doi:10.1007/s00216-012-6363-2, 2013.

Nishino, T., Ikemoto, E., Kogure, K.: Application of atomic force microscopy to observation of marine bacteria, J. Oceanogr., 60, 219-225, doi:10.1023/B:JOCE.0000038328.54339.e4, 2004.

Passow, U.: Transparent exopolymer particles (TEP) in aquatic environments, Prog. Oceanogr., 55, 287-333, doi:10.1016/S00796611(02)00138-6, 2002.

Pletikapić, G., Mišić Radić, T., Hozić Zimmermann, A., Svetličić, V., Pfannkuchen, M., Marić, D., Godrijan, J., and Žutić, V.: Extracellular polymer release AFM imaging of extracellular polymer release by marine diatom Cylindrotheca closterium (Ehrenberg) Reiman \& J. C. Lewin, J. Mol. Recognit., 24, 436-445, doi:10.1002/jmr.1114, 2011.

Pletikapić, G., Berquand, A., Mišić Radić, T., and Svetličić, V.: Quantitative nanomechanical mapping of marine diatom, J. Phycol., 48, 174-185, doi:10.1111/j.1529-8817.2011.01093.x, 2012a.

Pletikapić, G., Vinković Vrček, I., Žutić, V., and Svetličić, V.: Atomic force microscopy characterization of silver nanoparticles interactions with marine diatom cells and extracellular polymeric substance, J. Mol. Recognit., 25, 309-317, doi:10.1002/jmr.2177, 2012b.

Pletikapić, G., Svetličić, V., Lannon, H., Murvai, U., Kellermayer, M., and Brujić, J.: Self-assembly of polysaccharides gives rise to distinct mechanical signatures in marine gels, Biophys. J., 107, 355-364, doi:10.1016/j.bpj.2014.04.065, 2014.

Radić, T., Kraus, R., Fuks, D., Radić, J., and Pečar, O.: Transparent exopolymeric particles' distribution in the northern Adriatic and their relation to microphytoplankton biomass and composition, Sci. Total. Environ., 353, 151-161, doi:10.1016/j.scitotenv.2005.09.013, 2005.

Roth, V.-N., Dittmar, T., Gaupp, R., and Gleixner, G.: The Molecular composition of dissolved organic matter in forest soils as a function of $\mathrm{pH}$ and temperature, Plos One, 1-23, e0119188, doi:10.1371/journal.pone.0119188, 2015.

Santschi, P. H., Balnois, E., Wilkinson, K. J., Zhang, J., and Buffle, J.: Fibrillar polysaccharides in marine macromolecular organic matter as imaged by atomic force microscopy and transmission electron microscopy, Limnol. Oceanogr., 43, 896-908, doi:10.4319/lo.1998.43.5.0896, 1998.

Schon, P., Geerlings, J,; Tas, N., and Sarajlic, E.: AFM Cantilever with in situ renewable mercury microelectrode, Anal. Chem., 85, 8937-8942, doi:10.1021/ac400521p, 2013.

Schuster, S. and Herndl, G. J.: Formation and significance of transparent exopolymeric particles in the northern Adriatic Sea, Mar. Ecol.-Prog. Ser., 124, 227-236, doi:10.3354/meps124227, 1995.

Soler, N., Krupovic, M., Marguet, E., and Forterre, P.: Membrane vesicles in natural environments: a major challenge in viral ecology, ISME J., 9, 793-796; doi:10.1038/ismej.2014.184; 2015.

Stachowitsch, M., Fanuko, N., and Richter, M.: Mucus aggregates in the Adriatic Sea: An overview of stages and occurrences, Mar.
Ecol., 11, 327-350, doi:10.1111/j.1439-0485.1990.tb00387.x, 1990.

Svetličić, V., Ivošević, N., Kovač, S., and Žutić, V.: Charge displacement by adhesion and spreading of a cell, Bioelectrochemistry, 53, 79-86, doi:10.1016/S0302-4598(00)00115-X, 2001.

Svetličić, V., Žutić, V., and Hozić Zimmermann, A.: Biophysical scenario of giant gel formation in the northern Adriatic sea, Ann. N.Y. Acad. Sci., 1048, 524-527, doi:10.1196/annals.1342.082, 2005.

Svetličić, V., Balnois, E., Žutić, V., Chevalet, J., Hozić Zimmermann, A., Kovač, S., and Vdović, N: Electrochemical detection of gel microparticles in seawater, Croat. Chem. Acta, 79, 107113,2006

Svetličić, V., Žutić, V., Hozić Zimmermann, A., and Mišić, T.: Marine vesicles: Adhesion based detection of vesicles-like microparticles in seawater, Biophys. J., 94 (S), 655a-655a, 2008.

Svetličić, V., Žutić, V., Mišić Radić, T., Pletikapić, G., Hozić Zimmermann, A., and Urbani R.: Polymer networks produced by marine diatoms in the northern Adriatic sea, Mar. Drugs., 9, 666679, doi:10.3390/md9040666, 2011.

Svetličić, V., Žutić, V., Pletikapić, G., and Mišić Radić, T.: Marine polysaccharide networks and diatoms at the nanometric scale, Int. J. Mol. Sci., 14, 20064-20078, doi:10.3390/ijms141020064, 2013.

Tas, S. and Erdogan, O.: Effects of oil pollution on the phytoplankton community in the Kucukcekmece bay (north-east sea of Marmara, Turkey), Rapp. Comm. Int. Mer. Medit., 38, 320 320, 2007.

Tsekov, R., Kovač, S., and Žutić, V.: Attachment of oil droplets and cells on dropping mercury electrode, Langmuir, 15, 5649-5653, doi:10.1021/la980944q, 1999.

Urbani, R., Magaletti, E., Sist, P., and Cicero, A. M.: Extracellular carbohydrates released by the marine diatoms Cylindrotheca closterium, Thalassiosira pseudonana and Skeletonema costatum: effect of P-depletion and growth status, Sci. Total. Environ., 353, 300-306, doi:10.1016/j.scitotenv.2005.09.026, 2005.

Urbani, R., Sist, P., Pletikapić, G.; Mišić Radić, T., Svetličić, V., and Žutić, V.: Diatom polysaccharides: Extracellular roduction, isolation and molecular characterization, in: The complex world of polysaccharide, edited by: Karunaratn, D. N., Intech, Rijeka, Croatia, 346-356, doi:10.5772/51251, 2012.

Verdugo, P.: Marine microgels, Annu. Rev. Mar. Sci., 4, 375-400, doi:10.1146/annurev-marine-120709-142759, 2012.

Verdugo, P., Alldredge, A. L., Azam, F., Kirchman, D. L., Passow, U., and Santschi, P. H.: The oceanic gel phase: a bridge in the DOM-POM continuum, Mar. Chem., 92, 67-85, doi:10.1016/j.marchem.2004.06.017, 2004.

Villacorte, L. O., Ekowati, Y., Calix-Ponce, H. N., Schippers, J. C., Amy, G. L., and Kennedy, M. D.:Improved method for measuring transparent exopolymer particles (TEP) and their precursors in fresh and saline water, Water Res., 70, 300-312, doi:10.1016/j.watres.2014.12.012, 2015a.

Villacorte, L. O., Ekowati, Y., Neu, T. R., Kleijn, J. M., Winters, H., Amy, G., Schippers, J. C., and Kennedy, M. D. Characterisation of algal organic matter produced by bloomforming marine and freshwater algae, Water Res., 73, 216-230, doi:10.1016/j.watres.2015.01.028, 2015b.

Vollenweider, R. and Rinaldi, A.: Marine mucilages., Sci. Total. Environ., 165, 1-235, doi:10.1016/0048-9697(95)90002-0, 1999. 
Wang, Z., Zhang, L., Baoshan, J. and Xing, B.: Environmental processes and toxicity of metallic nanoparticles in aquatic systems as affected by natural organic matter, Environ. Sci.,3, 240-255, doi:10.1039/C5EN00230C, 2016.

Wells, M. L. and Goldberg, E. D.: Occurrence of small colloids in sea water, Nature, 353, 342-344, doi:10.1038/353342a0, 1991.

Wells, M. L. and Goldberg, E. D.: Colloid aggregation in seawater, Mar. Chem., 41, 353-358, doi:10.1016/0304-4203(93)90267-R, 1993.

Wells, M. L. and Goldberg, E. D.: The distribution of colloids in the North Atlantic and Southern Oceans, Limnol. Oceanogr., 39, 286-302, doi:10.4319/lo.1994.39.2.0286, 1994.

Žutić, V. and Legović, T.: A film of organic matter at the freshwater/sea-water interface of an estuary, Nature, 328, 612-614, doi:10.1038/328612a0, 1987.

Žutić, V. and Svetličić, V.: Interfacial processes, in: The Handbook of environmental chemistry, edited by: Wangersky, P., SpringerVerlag, Berlin, Germany, 149-165, 2000.

Žutić, V., Ćosović, B., and Kozarac, Z.: Electrochemical determination of surface active substances in natural waters, J. Electroanal. Chem., 78, 113-121, doi:10.1016/S00220728(77)80427-0, 1977.
Žutić, V., Pleše, T., Tomaić, J., and Legović, T.: Electrochemical characterization of fluid vesicles in natural waters, Mol. Cryst. Liq. Cryst., 113, 131-145, doi:10.1080/00268948408071678, 1984.

Žutić, V., Svetličić, V., and Tomaić, J.: Dissolved and dispersed organic matter in natural waters: Progress by electroanalysis, Pure Appl. Chem., 62, 2269-2276, doi:10.1351/pac199062122269, 1990.

Žutić, V., Kovač, S., Tomaić, J., and Svetličić, V.: Heterocoalescence between organic microdroplets and charged conductive interface, J. Electroanal. Chem., 349, 173-186, doi:10.1016/00220728(93)80171-D, 1993.

Žutić, V., Ivošević, N., Svetličić, V., Long, R. A., and Azam, F.: Film formation by marine bacteria at a model fluid interface. Aquat. Microb. Ecol., 17, 231-238, doi:10.3354/ame017231, 1999.

Žutić, V., Svetličić, V., Ivošević, N., Hozić, A., and Pečar, O.: Northern Adriatic mesocosm experiment Rovinj 2003: Dynamics of organic microparticles studied by the electrochemical technique, Period. Biol., 106, 67-74, 2004.

Zvonarić, T., Žutić, V., and Branica, M.: Determination of surfactant activity by polarography, Thalassia Jugosl., 9, 65-75, 1973. 